\title{
Cure kinetics of a polysilazane system: Experimental characterization and numerical modelling
}

\author{
Raffaele D’Elia a , Gilles Dusserre ${ }^{\mathrm{a}, *}$, Sylvie Del Confetto ${ }^{\mathrm{b}}$, Nicolas Eberling-Fux ${ }^{\mathrm{c}}$, \\ Cédric Descamps ${ }^{c}$, Thierry Cutard ${ }^{\text {a }}$
}

a Université de Toulouse, CNRS, Mines Albi, INSA, UPS, ISAE-SUPAERO, ICA (Institut Clément Ader), Campus Jarlard, F-81013 Albi, France

${ }^{\mathrm{b}}$ Université de Toulouse, CNRS, Mines Albi, Centre RAPSODEE - UMR CNRS 5302;Campus Jarlard, F-81013 Albi, France

${ }^{\mathrm{C}}$ SAFRAN-Herakles, Matériaux et Procédés CMC, CMB, France

\section{A B S T R A C T}

The Time-Temperature-Transformation (TTT) isothermal diagram is plotted for a polysilazane system, composed of the $\mathrm{KiON}^{\circledR}$ Ceraset $^{\circledR}$ Polysilazane 20 resin, with addition of $1 \mathrm{wt} \%$ of dicumyl peroxide acting as cross-linking catalyst. This diagram is useful to control the resin transfer moulding (RTM) process involved to obtain a composite material from a ceramic fibrous preform. The system under study is a precursor for the ceramic matrix, obtained after pyrolysis of the polymerized resin. The knowledge of the composite properties at the polymerized state is necessary to fully control this process. The cure kinetics of this system is investigated under both isothermal and dynamic curing conditions by Differential Scanning Calorimetry (DSC). The kinetics of the reaction is satisfactorily described by a Kamal and Sourour (K-S) phenomenological model. The K-S parameters are identified from isothermal data, taking into account an initial degree of cure, assuming a fully cured system at the end of the isothermal idle time. The model is in good agreement with both dynamic and isothermal experimental data. The glass transition temperature $\left(T_{g}\right)$ is determined by DSC analyses as a function of the degree of polymerization and confirmed by Dynamic Mechanical Analysis (DMA), and the results are modelled by Di Benedetto's formula. The change of visco-elastic properties is investigated using oscillatory rheology under isothermal conditions. The cure kinetics model allows a gelation criterion to be identified by plotting the shear loss modulus $G^{\prime \prime}$ vs. the degree of cure.

Keywords:

Polysilazane

Ceramic precursor

Gel point analysis

Cure kinetics

Phenomenological model

TTT diagrams

\section{Introduction}

In the last decades, the need of increasing operating temperatures and combustion efficiency of turbofan engines has led to study new ceramic materials for high-pressure turbine blades or combustor components, to improve thermo-mechanical and thermo-chemical properties. Ceramic Matrix Composites (CMC's) constitute a family of ceramic materials which combines high specific strength, high temperature resistance as well as damage tolerant behaviour. Several techniques are used to process CMC's, such as gas phase processing routes, ceramic processing routes and liquid phase processing routes. Among

\footnotetext{
* Corresponding author.

E-mail address: dusserre@mines-albi.fr (G. Dusserre).
} 
the latters, Polymer Impregnation and Pyrolysis (PIP) is a standard method to obtain carbon-carbon ceramic materials, but it is also applicable to SiC-based ceramics, with a dense and high purity $\beta$-SiC. This technique is composed of two steps: the injection of a polymer precursor in a fibrous preform and the ceramization of the composite through the pyrolysis of the precursors. Both phases are very important to optimize the process and obtain a final product with the highest density, together with avoiding process induced cracks.

Polyorganosilazanes are a family of precursors, used to prepare silicon carbo-nitrides $\left(\mathrm{Si}_{x} \mathrm{C}_{y} \mathrm{~N}_{z}\right)$ and related materials. They were introduced for the first time in 1885 [1], but were proposed only in the 1950s and 1960s as possible precursors for ceramic materials [2,3]. The growing interest in this class of materials arises from their application as silylating agents in synthetic chemistry and as single-source precursor for the preparation of ceramic materials [4]. The ceramic yield strongly depends on the molecular weight of the precursor. For this reason several authors at the turn of the 1980s and 1990s [5-10] worked on the modification of the silazane oligomers into non-volatile precursors, in order to increase the molecular weight of the polymer and to enhance the degree of cross-linking.

An interesting advantage of polysilazanes (and of all polymer precursors) is the possibility of using several forming methods, including polymer processing techniques, often more efficient than ceramic powders or pastes processing techniques. It is then possible to machine the polymer before ceramization, reducing the risk of a brittle fracture of the component. All plastic forming technologies are applicable to these precursors, like RTM, extrusion, injection moulding, etc.

Although several authors worked on the mechanical and physical characterization of polysilazane-derived ceramics [11-14], a significant lack of studies on the injection process of the precursor is observed. Viscosity evolution is directly driven by the polymerization of the system, influencing the choice of pressure, temperature and controlling the pot-life of the precursor. For this reason the characterization of polysilazane cross-linking is extremely important to improve material processing. This class of precursors is generally cured to solid at $100-250{ }^{\circ} \mathrm{C}[15,16]$ by simple heating, although cross-linking is also possible via UV curing method $[17,18]$. Lower curing temperatures are possible after addition of a radical initiator, which could be organic peroxide. Several authors used in particular dicumyl peroxide (DCPO) [16,1922 ], with concentration ranging from 0.01 to $5 \mathrm{wt} \%$ of the polymer [23-25].

The ceramic precursor used in this study is the KiON ${ }^{\circledR}$ Ceraset $^{\circledR}$ Polysilazane 20 (PSZ20), produced by Clariant ${ }^{\circledR}$. The shelf-life for this polymer, stored in a dark, $\operatorname{cool}\left(4^{\circ} \mathrm{C}\right)$ and dry place is 6 months [15]. The polymer is a pale yellow liquid. The density is $1-1.1 \mathrm{~g} / \mathrm{cm}^{3}$, with a viscosity of $180-750 \mathrm{mPa} \cdot \mathrm{s}\left(20^{\circ} \mathrm{C}\right)$. It can be converted into an amorphous Si/C/N material by pyrolysis at around $1000^{\circ} \mathrm{C}$. At higher temperatures $\left(>1400^{\circ} \mathrm{C}\right)$ the material crystallizes to form a nanocomposite of $\mathrm{SiC} / \mathrm{Si}_{3} \mathrm{~N}_{4} / \mathrm{C}$, which can be stable up to $180{ }^{\circ} \mathrm{C}$ [15]. The molecular structure of this polymer is characterized by an alternated $\mathrm{Si}-\mathrm{N}$ backbone with methyl $\mathrm{CH}_{3}(\sim 80 \%)$ and vinyl $\mathrm{CH}=\mathrm{CH}_{2}(\sim 20 \%)$ side groups (Fig. 1). Given this network the PSZ20 is also referred to as polymethylvinylsilazane.

Polysilazane cross-linking involves several chemical reactions, which are generally started by heating, because of a better control of the material curing and ceramic microstructure after pyrolysis. Reaction efficiency depends upon the reactive groups concentration: vinyl groups $\left(-\mathrm{CH}=\mathrm{CH}_{2}\right), \mathrm{Si}-\mathrm{H}, \mathrm{N}-\mathrm{H}$ are the principal groups that participate to the cross-linking of PSZ20. The possible reactions involved in the reticulation of this system are:

1. Vinyl group polyaddition:

$$
\mathrm{n}\left(\equiv \mathrm{Si}-\mathrm{CH}=\mathrm{CH}_{2}\right) \quad \rightarrow \quad-\left(\mathrm{CH}-\mathrm{CH}_{2}\right)_{n}
$$

2. Methyl/Vinyl radical reaction:

$$
\begin{aligned}
& \equiv \mathrm{Si}-\mathrm{CH}=\mathrm{CH}_{2}+\equiv \mathrm{Si}-\mathrm{CH}_{3} \rightarrow \quad \equiv \mathrm{Si}-\mathrm{CH}_{2}-\mathrm{CH}_{2}-\mathrm{CH}_{2}-\mathrm{Si} \equiv \\
& \text { and } \\
& \equiv \mathrm{Si}-\mathrm{CH}-\mathrm{CH}_{2}-\mathrm{Si} \equiv \\
& \text { I }
\end{aligned}
$$

3. Hydrosilylation:

$$
\begin{aligned}
& \equiv \mathrm{Si}-\mathrm{CH}=\mathrm{CH}_{2}+\equiv \mathrm{Si}-\mathrm{H} \rightarrow \quad \equiv \mathrm{Si}-\mathrm{CH}_{2}-\mathrm{CH}_{2}-\mathrm{Si} \equiv \\
& \text { and } \\
& \equiv \mathrm{Si}-\mathrm{CH}-\mathrm{Si} \equiv \\
& \mathrm{CH}_{3}
\end{aligned}
$$

4. Dehydrogenation $(\mathrm{Si}-\mathrm{H})$ :

$$
\equiv \mathrm{Si}-\mathrm{H}+\mathrm{H}-\mathrm{Si} \equiv \rightarrow \quad \equiv \mathrm{Si}-\mathrm{Si} \equiv+\stackrel{\nearrow}{\mathrm{H}_{2}}
$$


5. Dehydrogenation (Si-H with $\mathrm{N}-\mathrm{H})$ :

$$
\equiv \mathrm{Si}-\mathrm{H}+\equiv \mathrm{Si}-\mathrm{NH}-\mathrm{Si} \equiv \rightarrow \quad \equiv \mathrm{Si}-\mathrm{N}-\mathrm{Si} \equiv+\mathrm{H}_{2}
$$

6. Transamination:

$$
\begin{gathered}
2 \equiv \mathrm{Si}-\mathrm{NH}-\mathrm{Si} \equiv \rightarrow \equiv \mathrm{Si}-\mathrm{NH}_{2}+\equiv \mathrm{Si}-\underset{\mathrm{I}}{\mathrm{N}}-\mathrm{Si} \equiv \\
\mathrm{Si} \\
\mathrm{II} \\
\equiv \mathrm{Si}-\mathrm{NH}_{2}+\equiv \mathrm{Si}-\mathrm{NH}-\mathrm{Si} \equiv \rightarrow \quad \mathrm{Si}-\underset{\mathrm{N}}{\mid}-\mathrm{Si} \equiv+\underset{\mathrm{NH}_{3}}{\mathrm{Si}} \\
\|
\end{gathered}
$$

Lavedrine et al. [26] identified the reaction sequence at $120^{\circ} \mathrm{C}$ for this system as follows: hydrosilylation > dehydrogenation $(\mathrm{Si}-\mathrm{H} / \mathrm{N}-\mathrm{H}) \sim$ transamination $>$ vinyl group polyaddition $\sim$ dehydrogenation $(\mathrm{Si}-\mathrm{H})$.

Methyl/vinyl radical reactions take place between 200 and $300^{\circ} \mathrm{C}$ [27] and will not be considered in this work. The polyaddition of vinyl groups can be activated at lower temperature by the addition of a free radical generator as the DCPO. According to the literature [12,28], this reaction takes place at temperatures between 90 and $130{ }^{\circ} \mathrm{C}$ for a polymethylvinylsilazane resin with addition of $0.1 \mathrm{wt} \%$ of DCPO. After addition of $1 \mathrm{wt} \%$ of DCPO, vinyl polyaddition is promoted to the detriment of dehydrogenation.

Several authors have studied ceramic materials obtained using this family of polymers, characterizing their microstructures and mechanical and physical properties [11-13,29]. However, before the pyrolysis, a preform of SiC-based ceramic fibers is impregnated by the polymer precursor, using RTM (Resin Transfer Moulding). During this phase, cure kinetics of precursor is fundamental, because of the need to completely fill the preform to obtain the highest material density and best mechanical properties. Time-Temperature-Transformation (TTT) isothermal diagram is a widely used tool to compute RTM parameters as temperature and pressure of injection. This paper will focus on the cure kinetics of PSZ20 precursor, to finally plot the TTT diagram of the system.

\section{Experimental}

The polysilazane precursor (PSZ20 - Clariant $\left.^{\circledR}\right)$ and the dicumyl peroxide $\left(\mathrm{C}_{18} \mathrm{H}_{22} \mathrm{O}_{2}, 270.37 \mathrm{~g} / \mathrm{mol}\right.$ - Sigma Aldrich $\left.{ }^{\circledR}\right)$ are stored in a dry, dark and $\operatorname{cool}\left(4^{\circ} \mathrm{C}\right)$ place before use. Samples are prepared by mixing PSZ20 with $1 \mathrm{wt} \%$ of dicumyl peroxide using a magnetic stirrer up to the complete dissolution of the peroxide. This operation takes $1 \mathrm{~h}$ at $293 \mathrm{~K}\left(20^{\circ} \mathrm{C}\right)$. At the end of this process, the compound presents a great amount of bubbles, generated by the mixing. Bubbles could affect DSC or rheology test results: for this reason the compound is kept at $277 \mathrm{~K}\left(4^{\circ} \mathrm{C}\right)$ during $12 \mathrm{~h}$ at least before the test. At the end of this procedure, the material is ready to be studied using different techniques. The study of the cure kinetics of the system is performed using a Differential Scanning Calorimetry. A DSC-Q200 of TA Instruments is used to measure the total heat of polymerization $\left(\Delta H_{\text {tot }}\right)$ for different heating rates, the glass transition temperature $\left(T_{g}\right)$ after several interrupted isothermal cures, and the residual heat of reaction $\left(\Delta H_{\text {res }}\right)$.

The initial heating rate (from $293 \mathrm{~K}$ to $T_{\text {curing }}$ ) of isothermal cure is chosen to reduce temperature overshoot of the sample. The initial mass of the samples, placed in a non-hermetic crucible, ranges between 10 and $20 \mathrm{mg}$ and the tests are performed under continuous $\mathrm{N}_{2}$ flow $(50 \mathrm{ml} / \mathrm{min}$ ). Isothermal curing is carried out at four different temperatures ranging from $363 \mathrm{~K}$ $\left(90^{\circ} \mathrm{C}\right)$ to $393 \mathrm{~K}\left(120^{\circ} \mathrm{C}\right)$ and with a curing time ranging from $5 \mathrm{~min}$ to $48 \mathrm{~h}$. After isothermal curing, the samples are quenched from $T_{\text {curing }}$ to $183 \mathrm{~K}\left(-90^{\circ} \mathrm{C}\right)$ at a rate of $200 \mathrm{~K} / \mathrm{min}$. After $20 \mathrm{~min}$ at $183 \mathrm{~K}$, necessary to stabilize the modulation conditions, a modulated DSC scan is performed at $2 \mathrm{~K} / \mathrm{min}$, with period of $40 \mathrm{~s}$ and amplitude of $0.8 \mathrm{~K}$, from $183 \mathrm{~K}\left(-90^{\circ} \mathrm{C}\right)$ to

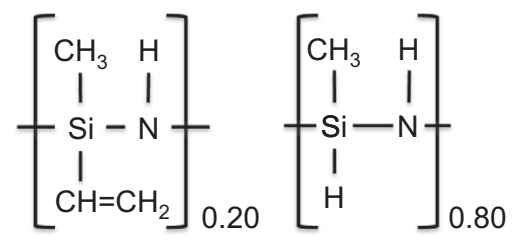

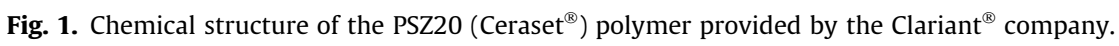




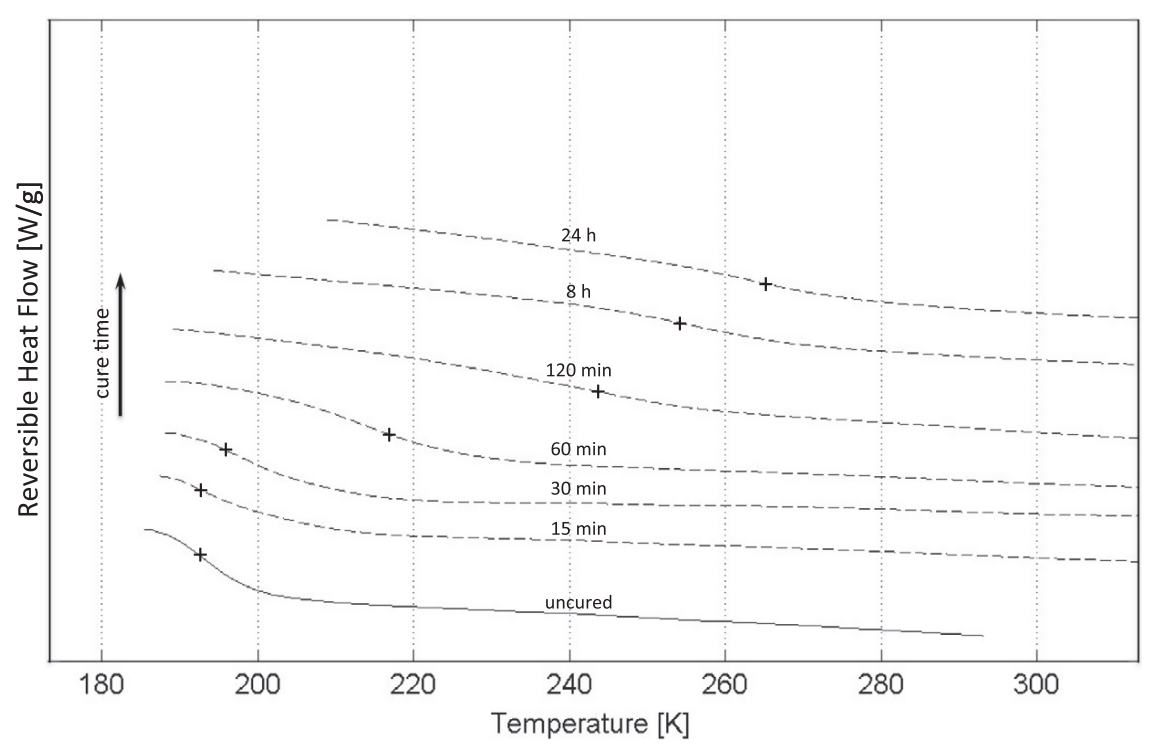

Fig. 2. DSC scans between $183 \mathrm{~K}\left(-90^{\circ} \mathrm{C}\right)$ and $293 \mathrm{~K}\left(20^{\circ} \mathrm{C}\right)$ after different isothermal cure at $383 \mathrm{~K}\left(110^{\circ} \mathrm{C}\right)$ : glass transition temperature of the system (Reversible Heat Flow). The symbol + shows the $T_{g}$ location at each cure time.

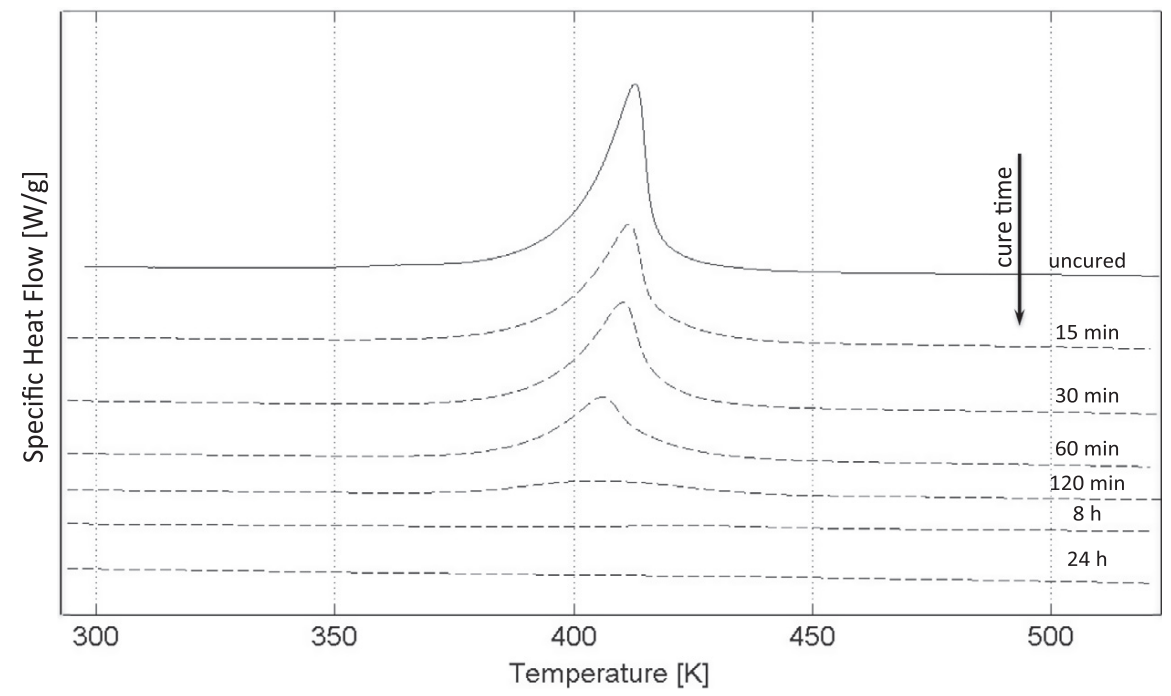

Fig. 3. DSC scans between $293 \mathrm{~K}\left(20^{\circ} \mathrm{C}\right)$ and $523 \mathrm{~K}\left(250^{\circ} \mathrm{C}\right)$ after different isothermal cures at $383 \mathrm{~K}\left(110^{\circ} \mathrm{C}\right)$ : residual heat of reaction of the system $\left(\Delta H_{r e s}\right)$.

$573 \mathrm{~K}\left(300^{\circ} \mathrm{C}\right)$. These conditions are chosen in order to obtain the glass transition temperature of the system (Fig. 2), defined as the midpoint of the step transition on the reversible signal of heat flow. Modulation was necessary due to the low amplitude of these step transitions. The residual heat of reaction (Fig. 3) is calculated as the time integral of the residual peak of the overall heat flow.

Isothermal cure kinetics is necessary to identify two important transformations of the material: the vitrification point and the gelation point. Vitrification takes place when the glass transition temperature attains the test temperature, with the material that passes from a rubbery state to a vitreous state. Gelation occurs when the network built by cross-linking becomes continuous and occupies all the volume. At this point a lot of chains are still free of bonding, and the material is considered in a gel state [30]. Gelation will be characterized using a rheometer HAAKE MARS of ThermoScientific, under oscillatory rheology conditions and using a plane/plane configuration. These tests were performed under isothermal conditions at four different temperatures $(363 \mathrm{~K}, 373 \mathrm{~K}, 383 \mathrm{~K}, 393 \mathrm{~K}$ ) with a frequency of $1 \mathrm{~Hz}$.

\section{Results and discussion}

\subsection{Heat of polymerization}

The total heat of polymerization $\left(\Delta H_{t o t}\right)$ was measured during several anisothermal scans, performed at $0.5 \mathrm{~K} / \mathrm{min}$, $2 \mathrm{~K} / \mathrm{min}, 5 \mathrm{~K} / \mathrm{min}$ and $10 \mathrm{~K} / \mathrm{min}$ from $293 \mathrm{~K}$ to $473 \mathrm{~K}$. The results of these tests are shown in Fig. 4. 


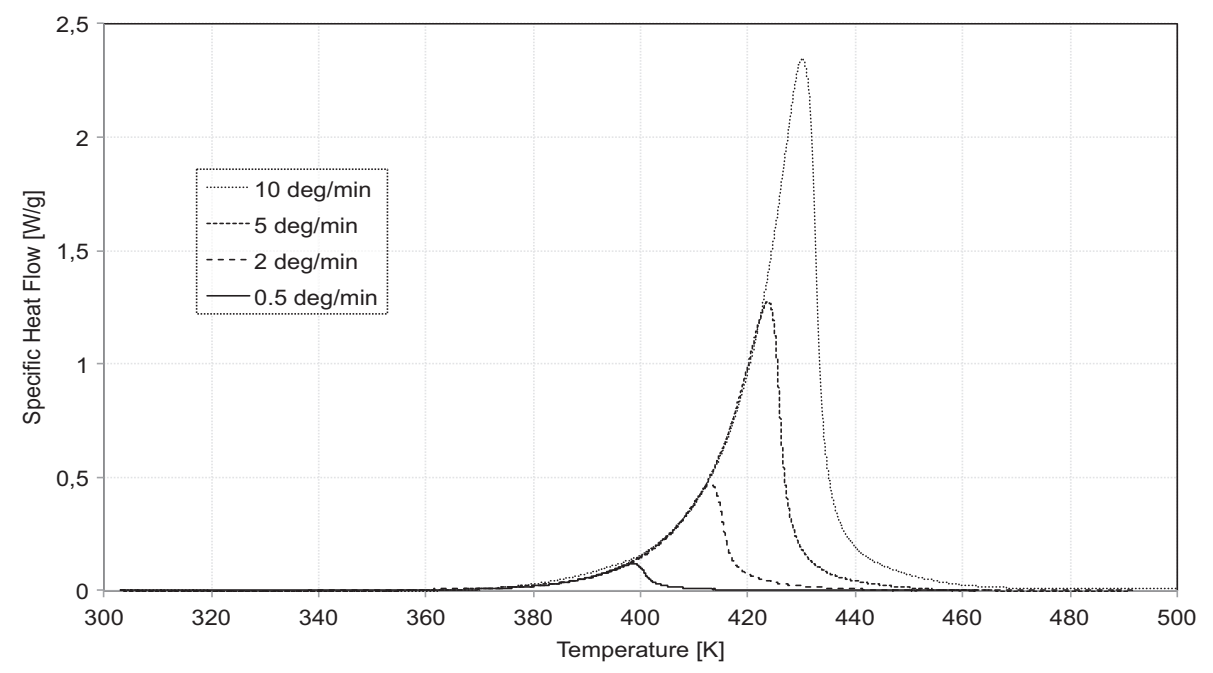

Fig. 4. Total heat of polymerization obtained at different heating rates.

$\Delta H_{\text {tot }}$ represents the specific heat generated during the exothermal reaction of polymerization per one gram of solution. It is calculated as the integral of the specific heat flow $(\dot{H})$ with respect to the time of reaction (Eq. (1)), and the mean value obtained for this system is $228.5( \pm 6.1) \mathrm{J} / \mathrm{g}$.

$$
\Delta H_{t o t}=\int_{0}^{t_{f}} \dot{H} d t
$$

\subsection{Glass transition temperature}

The glass transition temperature $\left(T_{g}\right)$ and the residual heat of reaction $\left(\Delta H_{\text {res }}\right)$ after several idle times at several temperatures are determined from interrupted isothermal tests, in order to identify a Di Benedetto's formula. The degree of cure corresponding to each $T_{g}$ value is then computed with the following formula:

$$
\alpha=1-\frac{\Delta H_{\text {res }}}{\Delta H_{\text {tot }}}
$$

The $T_{g}$ value can be related to the degree of cure using the Di Benedetto's equation [31]:

$$
\begin{aligned}
& T_{g}=T_{g_{0}}+\left(T_{g_{\infty}}-T_{g_{0}}\right) \cdot \frac{\alpha \lambda}{1-(1-\lambda) \alpha} \\
& \lambda=\frac{F_{x}}{F_{m}}
\end{aligned}
$$

where $T_{g 0}$ and $T_{g_{\infty}}$ are respectively the glass transition temperatures for uncrosslinked $(\alpha=0)$ and fully crosslinked polymer $(\alpha=1), F_{m}$ and $F_{x}$ are the segmental mobility of the corresponding physical states.

According to Pascault and Williams [32], and following the Couchman entropy based approach to mixtures, the $\lambda$ parameter in Di Benedetto's equation can also be defined as the ratio between the change in the isobaric heat capacities through the glass transition for a fully cured system $\left(\Delta C_{p \infty}\right)$ and for an uncured system $\left(\Delta C_{p 0}\right)$ :

$$
\lambda=\frac{\Delta C_{p \infty}}{\Delta C_{p 0}}
$$

The experimental observation stating that the product $\Delta C_{p} \cdot T_{g}$ is approximately constant [33] was checked to apply to PSZ20. In the present study the mean value of $\Delta C_{p} \cdot T_{g}$ is $55.9( \pm 7.6) \mathrm{J} / \mathrm{g}$. The slope of a linear regression of a $\Delta C_{p} \cdot T_{g}$ versus alpha plot is $3.8 \mathrm{~J} / \mathrm{g}$ (6.8\% of the mean value), which confirms the hypothesis of constancy of the product $\Delta C_{p} \cdot T_{g}$. According to these considerations, Di Benedetto's equation reduces to a mixing law for the change in isobaric heat capacity through the glass transition:

$$
\Delta C_{p}=\Delta C_{p 0}+\alpha\left(\Delta C_{p \infty}-\Delta C_{p 0}\right)
$$

This equation can be used to evaluate $\Delta C_{p 0}$ and $\Delta C_{p \infty}$ from the experimental plot of $\Delta C_{p}$ as a function of the degree of cure even if both values are not very accurately measured directly, and then calculate the parameter $\lambda$ from Eq. (4) (Fig. 5). This method leads to a value of $\lambda$ of $0.74\left(\Delta C_{p 0}=0.297 \mathrm{~J} \cdot \mathrm{g}^{-1} \mathrm{~K}^{-1}\right.$ and $\left.\Delta C_{p \infty}=0.220 \mathrm{~J} \cdot \mathrm{g}^{-1} \mathrm{~K}^{-1}\right)$ and a determination coefficient $R^{2}$ of 


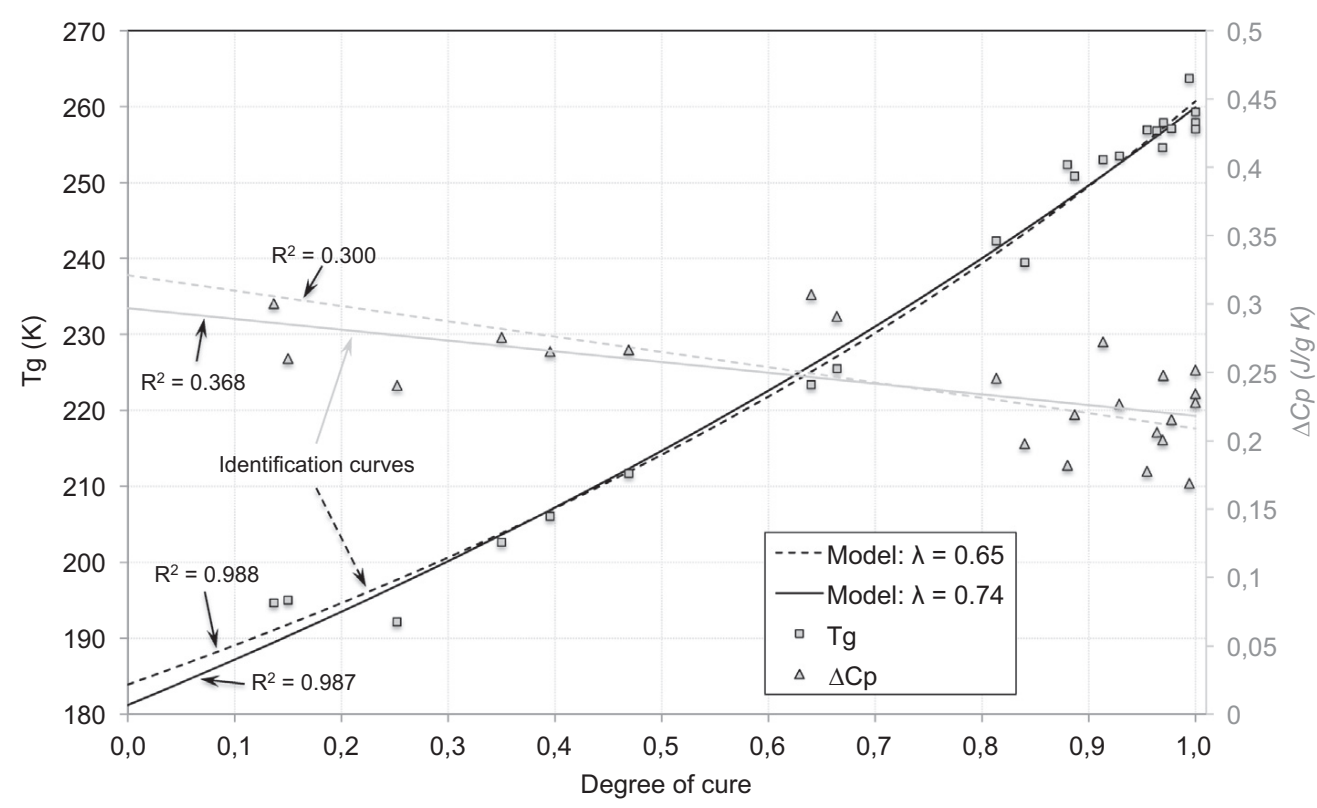

Fig. 5. Di Benedetto's plots for the system $\left(T_{g}\right.$ and $\left.\Delta C_{p}\right)$, using a $\lambda$ of 0.65 and 0.74 .

0.368 (Fig. 5). The strong dispersion in the $\Delta C_{p}$ experimental data leads to consider a second method of identification, in order to confirm the Pascault-Williams (P-W) method. For this reason, a linearization of Eq. (3) has been operated, to obtain the best fitting results, through a multiple linear regression analysis:

$$
T_{g}=A+B \cdot X
$$

with $A=T_{g_{0}}, B=\left(T_{g_{\infty}}-T_{g_{0}}\right)$ and $X=\frac{\alpha \lambda}{1-(1-\lambda) \alpha}$. It is possible to plot this straight line for different values of $\lambda$ : the value giving the best determination coefficient $R^{2}$ will represent the best fitting of the Di Benedetto's formula for this system. The $\lambda$ giving the best fit is $0.65\left(R^{2}=0.988\right)$, although the residual remains roughly constant for $\lambda$ ranging between 0.6 and 0.75 . However a value of 0.65 significantly reduces the determination coefficient for the $\Delta C_{p}$ curve (from 0.368 to 0.300 , Fig. 5). For this reason the $\lambda$ obtained with the P-W method is finally considered as the most relevant value.

The following parameters are obtained using a $\lambda$ of $0.74: T_{g 0}=181.2 \mathrm{~K}, T_{g_{\infty}}=259.9 \mathrm{~K}$, with the corresponding Di Benedetto's plot presented in Fig. 5. This result represents the optimum according to the linearization analysis and to the physical meaning of the parameter $\lambda$ described by Pascault and Williams [32].

To confirm the value of $T_{g \infty}$, a DMA (Dynamical Mechanical Analysis) 8000 of Perkin Elmer, under continuous $\mathrm{N}_{2}$ flow has been used on composite samples cured at $393 \mathrm{~K}\left(120^{\circ} \mathrm{C}\right)$ during 2,12 or $18 \mathrm{~h}$. The degree of cure is expected to be 1 in these conditions. The size of the samples used for DMA is $4 \times 4 \times 50 \mathrm{~mm}^{3}$. Fibers have been included in the polymer in order to unmould the samples from the silicone mould used to cast the liquid polymer before curing. The use of composite material was necessary, since it was not possible to easily obtain samples made only with the catalyzed polymer. Fibers in composite do not affect the mechanical manifestation of the glass transition, which depends only on the matrix. For this system $T_{g}$ is found to match the onset point of the storage modulus decrease. An average onset temperature of $263 \mathrm{~K}$ is obtained, which corroborates the $T_{g_{\infty}}$ value obtained using DSC analyses (259.9 K).

\subsection{Cure kinetics modelling}

Isothermal DSC curves are used to identify the parameters of a phenomenological Kamal-Sourour model, Eq. (7). This approach is chosen to be representative of the isothermal conditions of injection of the polymer precursor, during RTM processing.

$$
\frac{d \alpha}{d t}=\left(k_{1}+k_{2} \alpha^{m}\right)(1-\alpha)^{n}
$$

This model assumes two rate constants [34], $k_{1}$ and $k_{2}$, Eq. (8), which follow an Arrhenius dependence to temperature.

$$
k_{i}(T)=k_{o i} \exp \left(\frac{-E_{a i}}{R T}\right) \quad i=1,2
$$

$m$ and $n$ are the reaction orders. Several authors used this law to model epoxy resins polymerization [35-37] or silicone rubber vulcanization [38], because of the autocatalytic and catalytic nature of the reactions driving the crosslinking of these systems and conferring a general purpose to this phenomenological model. Some authors [36,37] coupled a diffusion term to 
the Kamal-Sourour model, in order to take into account the reaction rate decrease at vitrification, when $T_{g}$ attains the testing temperature. However, maximal glass transition temperature, $T_{g_{\infty}}$, of the system under study is $259.9 \mathrm{~K}\left(-13.1^{\circ} \mathrm{C}\right)$, which is far lower than the isothermal curing temperatures used in this paper and more generally while composite processing. For this reason, the diffusion-controlled mechanism will not be considered to model the material behaviour.

Before isothermal curing, the material undergoes a heating ramp, which is chosen in order to reduce temperature overshoot at the beginning of the isothermal dwell. This step is generally neglected in the processing of DSC isothermal data, but it results in an initial degree of cure of the system $\alpha\left(t_{0}\right)$, which is not negligible in our experiments. This approximation would imply an error on the parameters of the model, reducing its accuracy. In this paper an initial degree of cure is considered, in order to take into account the reaction advancement during the initial heating rate of the sample. This is made using the hypothesis that the reaction advancement is complete at the end of the isothermal curing, which leads to Eq. (9).

$$
\alpha\left(t_{0}\right)=\alpha_{0}=1-\frac{\int_{t_{0}}^{t_{f}} \dot{H} d t}{H_{\text {tot }}}
$$

$\dot{H}$ is the specific heat flow generated during isothermal curing, $t_{0}$ is the time necessary to reach the isothermal conditions, $t_{f}$ is the final time of the test.

The parameters of the Kamal-Sourour model were identified on the isothermal curves, using a Nelder-Mead simplex direct search $[39,40]$, through the MatLab ${ }^{\circledR}$ subroutine fminsearch. The objective function of this unconstrained multivariable optimization is the normalized difference between the numerical solution and the experimental data. The optimized set of parameters is reported in Table 1.

As shown in Fig. 6, both rate constants, $k_{1}$ and $k_{2}$, follow almost perfectly an Arrhenius trend, with correlation coefficients $R^{2}$ higher than 0.999 .

From the fitting line equation, it is possible to obtain the activation energies (the slope of the line is $-E_{a} / R$, with $R=8.3144 \mathrm{~J} \mathrm{~mol}^{-1} \mathrm{~K}^{-1}$ ) and the pre-exponential factor (intercept of the line) of the rate constants. At contrary, the reaction orders $\mathrm{n}$ and $\mathrm{m}$, doesn't exhibit any significant temperature trend, and the mean values are taken to obtain a global modelling of the system. The parameters of the global Kamal-Sourour model are summarized in Table 2.

For validation purpose, the identified Kamal-Sourour model is compared to experimental data in both isothermal and dynamic conditions, using either the specific heat flow $\dot{H}$ or the degree of cure $\alpha$. The results are plotted in Figs. 7-9, where the discontinuous lines represent the experimental data and the continuous lines represent Kamal-Sourour model results.

The identified model is in very good agreement with both isothermal (gap < 4\%) and dynamic (gap <6\%) experiments, irrespective of the test conditions. In isothermal conditions it is possible to notice the influence of the initial degree of cure $\alpha_{0}$, used to correct the error introduced by the initial heating ramp of the sample, which makes starting the curves at a value higher than zero (Fig. 7). The dynamic tests (Figs. 8 and 9) are also in good agreement with modelling, although the model attains the total conversion faster than experimental data for all the heating rates $(0.5,2,5 \mathrm{and} 10 \mathrm{~K} / \mathrm{min})$. The mismatch between experience and model increases starting from a degree of cure of 0.9 . This discrepancy possibly results from several factors. Among them, the hypothesis of a complete conversion at the end of the isothermal experiments is probably not fully valid. More probably, the reaction mechanism, including a first step of dicumyl peroxide degradation, followed by the polysilazane resin polymerization, is too complex to be perfectly described by a Kamal-Sourour model. A better description of the whole kinetics would necessitate studying separately the two mechanisms by carrying out a coupled approach, involving an identification of the polymerization parameters once the degradation has been described with another phenomenological model. A larger amount of work would be necessary to build a mechanistic approach, since the degradation of dicumyl peroxide, alone, involves about 50 reactions [41].

Although the trend of the model does not properly match the experiment at the end of cure (for $\alpha>0.9$ ), this does not prevent to use the model for a large range of degree of cure, to simulate the gelation of the system, and for the highest conversion rate, where the reaction mechanism is the fastest. It is therefore considered that the global Kamal-Sourour model identified describes satisfactorily the polymerization kinetics of the system, and in particular in the range where gelation occurs, which is one of the most important feature of a TTT diagram for process control purpose.

\subsection{Gelation point analysis}

During the isothermal curing of the system, the viscosity increases continuously with time, because of the crosslinking of the system. The gelation point is a key process parameter, because it gives some useful information for material processing,

Table 1

Kamal-Sourour parameters for isothermal modelling.

\begin{tabular}{llllll}
\hline$t_{\text {curing }}(\mathrm{h})$ & $T_{\text {curing }}\left({ }^{\circ} \mathrm{C}\right)$ & $k_{1}\left(\mathrm{~s}^{-1}\right)$ & $k_{2}\left(\mathrm{~s}^{-1}\right)$ & $m$ & $\alpha_{0}$ \\
\hline 48 & 90 & $1.92 \cdot 10^{-5}$ & $7.78 \cdot 10^{-5}$ & 2.56 & 0.14 \\
30 & 100 & $5.54 \cdot 10^{-5}$ & $2.96 \cdot 10^{-4}$ & 2.76 & 1.28 \\
24 & 110 & $1.60 \cdot 10^{-4}$ & $9.35 \cdot 10^{-4}$ & 2.98 & 0.16 \\
4 & 120 & $4.62 \cdot 10^{-4}$ & $2.80 \cdot 10^{-3}$ & 0.19 & 2.56 \\
\hline
\end{tabular}




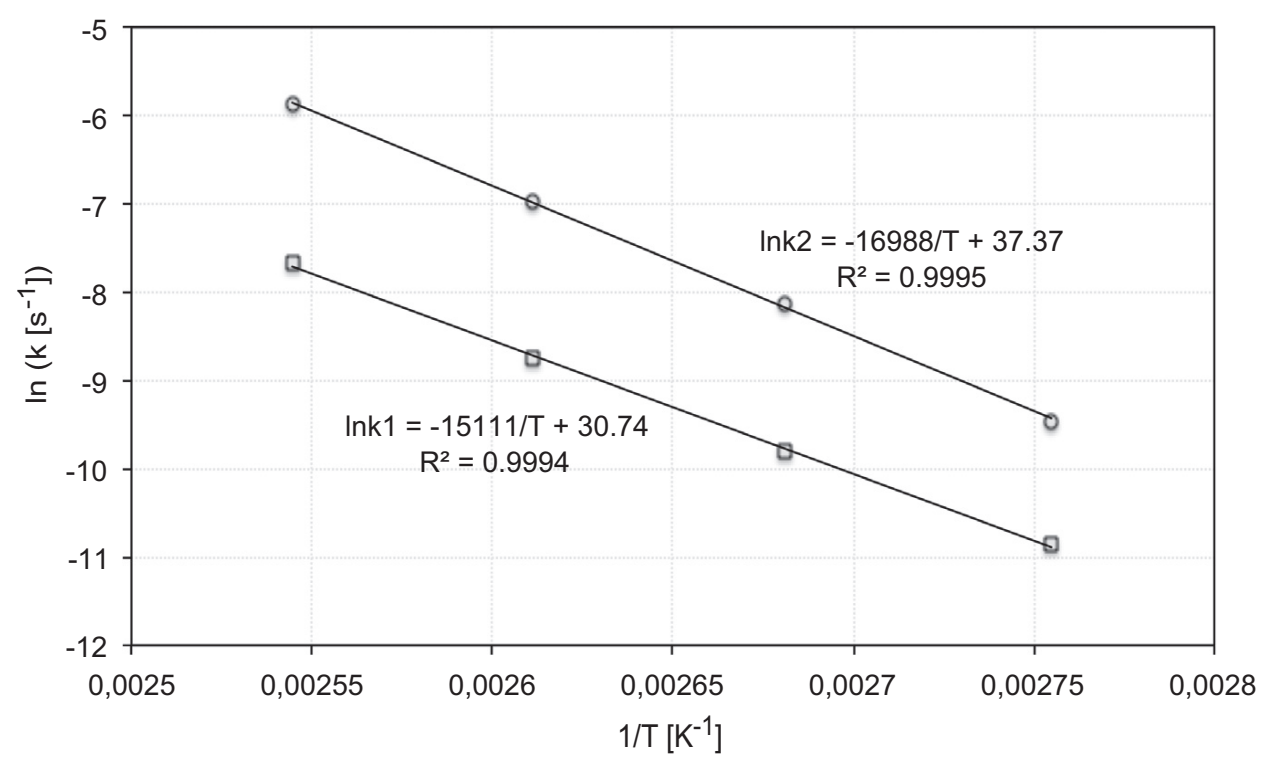

Fig. 6. Arrhenius plots of the two rate constants of the system, according to a Kamal-Sourour model.

Table 2

Kamal-Sourour parameters obtained with isothermal identification.

\begin{tabular}{ll} 
- $k_{o 1}=2.24 \cdot 10^{13} \mathrm{~s}^{-1}$ & $\bullet k_{o 2}=1.70 \cdot 10^{16} \mathrm{~s}^{-1}$ \\
- $E_{o 1}=125.64 \mathrm{~kJ} / \mathrm{mol}$ & $\bullet E_{o 2}=141.25 \mathrm{~kJ} / \mathrm{mol}$ \\
- $m=2.71$ & $\bullet n=1.38$ \\
\hline
\end{tabular}

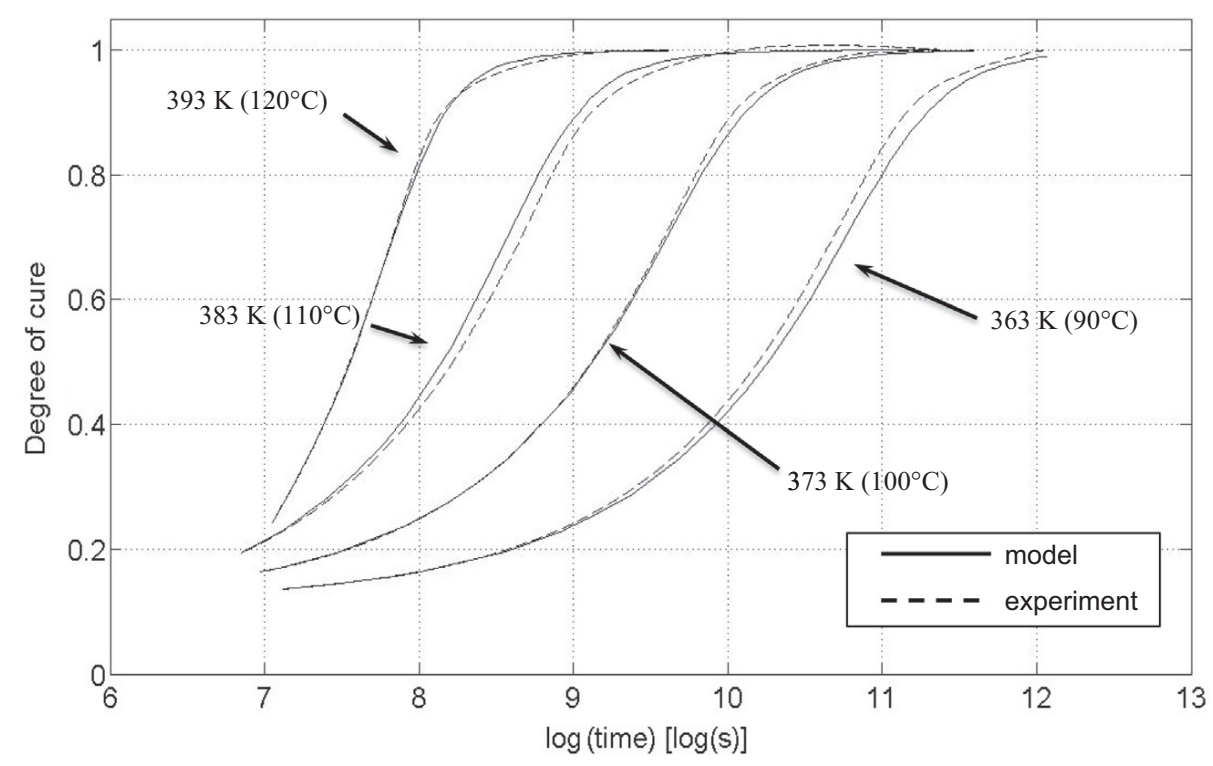

Fig. 7. Validation of Kamal-Sourour model using isothermal curing: degree of cure vs. $\log ($ time).

especially for liquid composites moulding. This parameter is commonly identified from oscillatory rheology tests by using a criterion based on the viscoelastic properties of the fluid, which change with the crosslinking advancement. According to the literature, several criteria are used to define the gelation point of a material: a given viscosity value [42], the criterion of the maximum derivative of the viscosity [35], the $G^{\prime \prime}$ inflexion criterion [30], the crossover between the $G^{\prime}$ and $G^{\prime \prime}$ curves or between the $\tan \delta$ vs. time curves at different frequencies [43]. To investigate these criteria some time sweep oscillatory tests were performed with a frequency of $1 \mathrm{~Hz}$ and a strain amplitude of $1 \%$. During these tests, the following equations hold: 


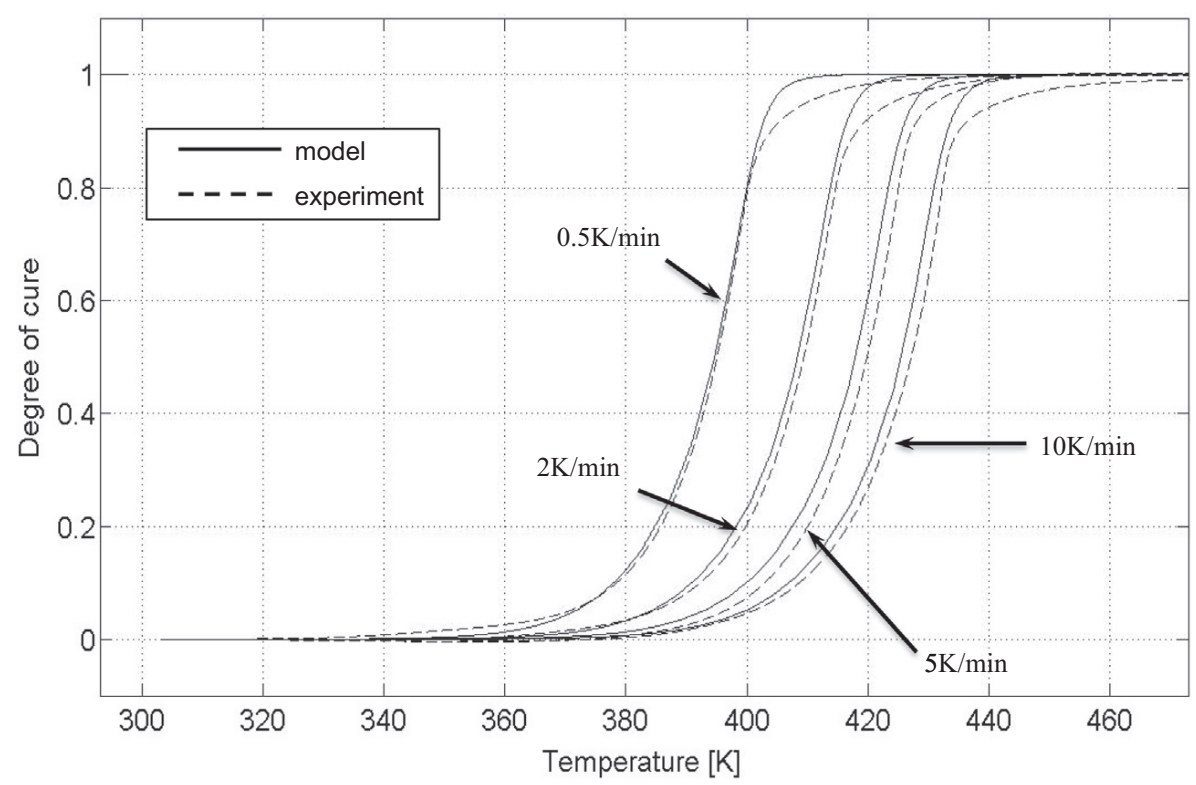

Fig. 8. Dynamic validation of the global Kamal-Sourour model: degree of cure vs. temperature.

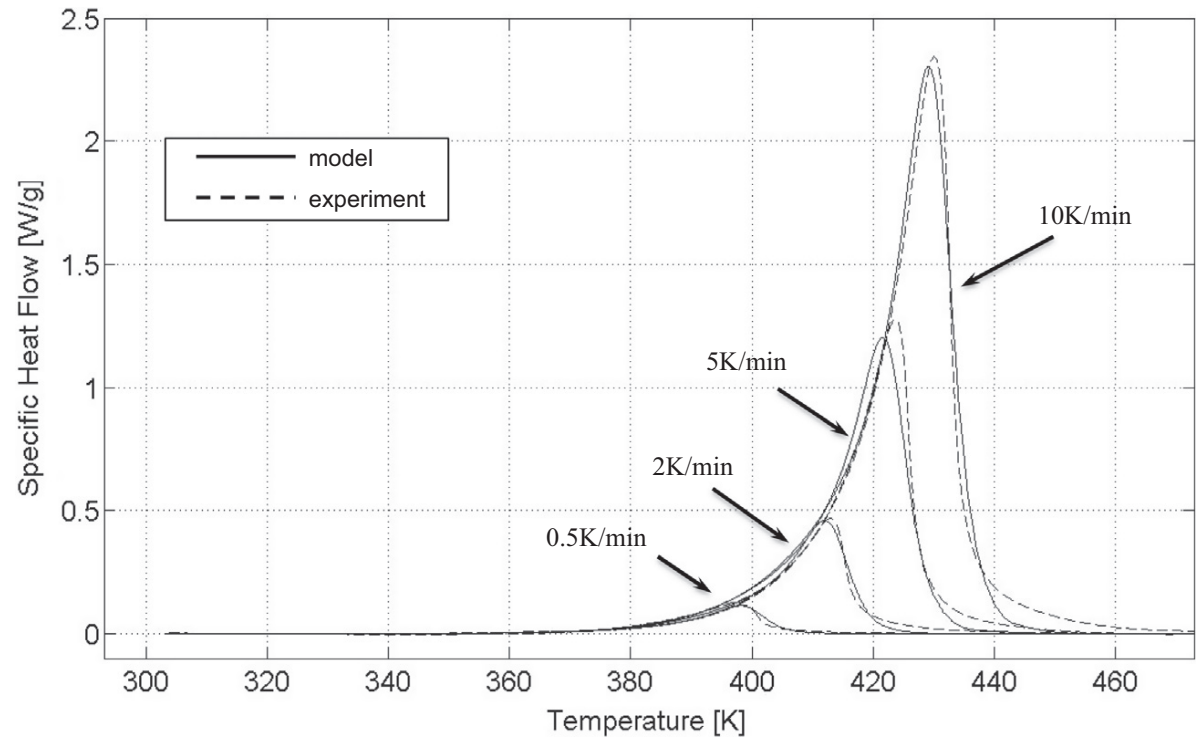

Fig. 9. Dynamic validation of the global Kamal-Sourour model: heat flow vs. temperature.

$$
\begin{aligned}
& \bar{\varepsilon}(t)=\varepsilon_{0} e^{i(\omega t)} \\
& \bar{\tau}(t)=\tau_{0} e^{i(\omega t+\delta)}
\end{aligned}
$$

A sinusoidal strain $\varepsilon(t)$, with an amplitude $\varepsilon_{0}$ and a pulsation $\omega$ is applied to the polymer. The tests are performed in a plane/plane configuration. The system will react to this solicitation with a sinusoidal stress $\tau(t)$, with an amplitude $\tau_{0}$ and pulsation $\omega$, shifted of an angle $\delta$ with regard to the strain. $\delta$ is the loss angle. The complex shear modulus $(\bar{G})$ and the complex viscosity $(\bar{\eta})$ can be computed according to Eq. (11), where $G^{\prime}$ is the elastic shear modulus (or storage modulus), and $G^{\prime \prime}$ is the viscous shear modulus (or loss modulus).

$$
\begin{aligned}
\bar{G}(\omega) & =\frac{\bar{\tau}(t)}{\overline{\bar{\varepsilon}}(t)}=G^{\prime}(\omega)+i G^{\prime \prime}(\omega) \\
\bar{\eta}(\omega) & =\frac{\bar{G}(\omega)}{i \omega}
\end{aligned}
$$




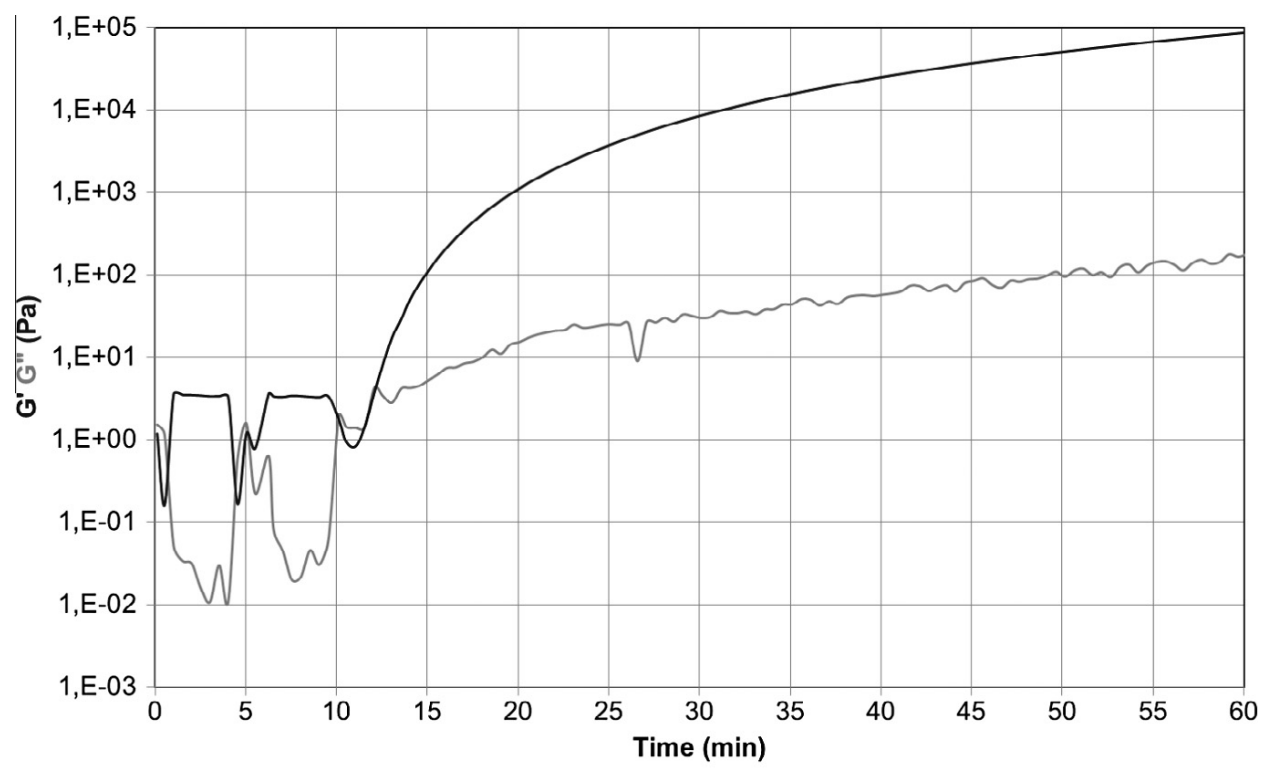

Fig. 10. Example of $G^{\prime} / G^{\prime \prime}$ vs. time plot for the isothermal test performed at $100{ }^{\circ} \mathrm{C}$. The rheological tests were designed to monitor the high viscosity range and the results must not be considered before $12 \mathrm{~min}$ in this figure.

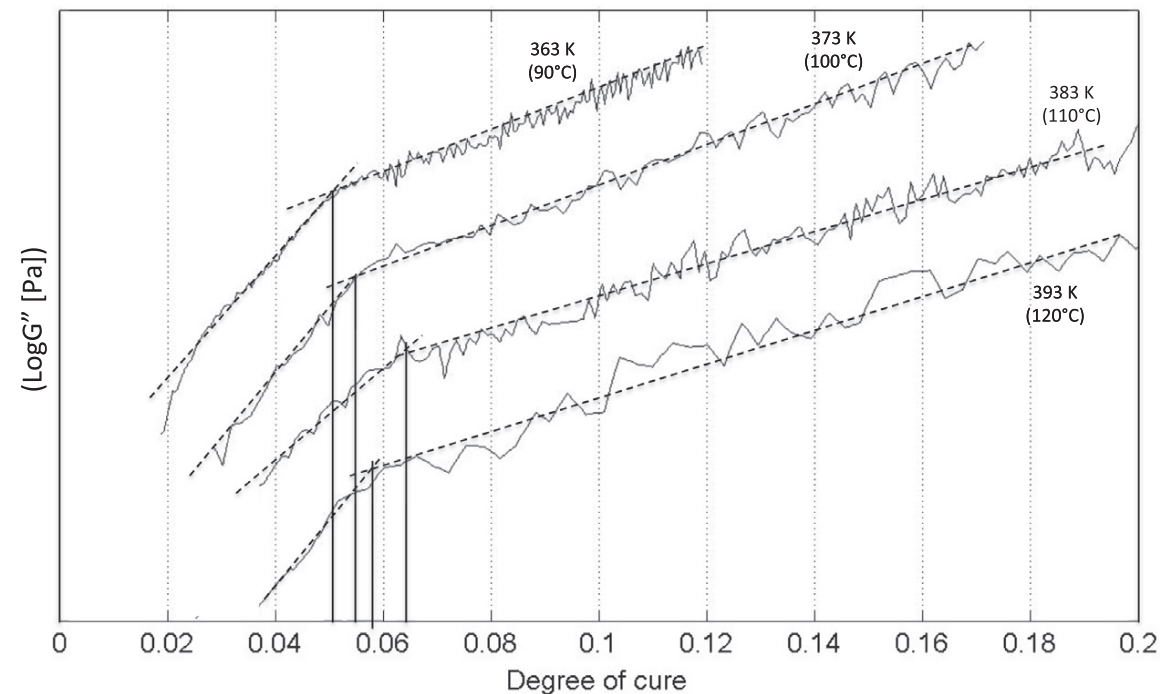

Fig. 11. Loss moduli vs. degree of cure for different isothermal conditions, according to Kamal-Sourour global model and to oscillatory rheology tests.

The cross-point of $G^{\prime}$ and $G^{\prime \prime}$, which is the most commonly used gel point criterion $[44,45]$, was found to occur very early (for polymerization degree lower than $1 \%$ ) and did not allow a convincing criterion common to all experiment to be identified. This can be observed in Fig. 10, where the plot of $G^{\prime}$ and $G^{\prime \prime}$ vs. time for an isothermal test at $100{ }^{\circ} \mathrm{C}$ is presented. Similar results are obtained for the other isothermal curves. Even if the test parameters were not chosen to properly identify this criterion, occurring for too low viscosity, Fig. 10 shows that $G^{\prime}$ becomes higher than $G^{\prime \prime}$ at the very early instant of polymerization and was not further investigated.

The most relevant criterion to describe the polysilazane gelation was found to be the Harran and Laudouard criterion [30], which matches the gelation point to the inflection of the loss modulus $\left(G^{\prime \prime}\right)$ curve vs. time.

Oscillatory rheology curves were obtained under four isothermal conditions: $363 \mathrm{~K}\left(90^{\circ} \mathrm{C}\right), 373 \mathrm{~K}\left(100{ }^{\circ} \mathrm{C}\right), 383 \mathrm{~K}\left(110^{\circ} \mathrm{C}\right)$ and $393 \mathrm{~K}\left(120^{\circ} \mathrm{C}\right)$. The initial heating rate, necessary to reach the isothermal temperature, is programmed by a PID controller to minimize temperature overshoot at the beginning of the isothermal curing.

According to the Kamal-Sourour global model it is possible to calculate the degree of cure $(\alpha)$, integrating the differential equation of the reaction rate $\left(\frac{d \alpha}{d t}\right)$ with a Runge-Kutta $(4,5)$ explicit method, the Dormand-Price pair, using the ODE45 MatLab $^{\circledR}$ subroutine [46]. This integration is made at each time step, using the experimental time-temperature curves coming from the results of rheological tests. The four curves presenting the loss modulus vs. degree of cure are presented in Fig. 11. The gelation point has been obtained as the crossover of the two straight fitting lines before and after the inflexion, according to the following equations: 
Table 3

Gel time, degree of cure at gel point and correlation coefficients for each isothermal curing temperature.

\begin{tabular}{llll}
\hline$T_{\text {curing }}\left({ }^{\circ} \mathrm{C}\right)$ & $\alpha_{\text {gel }}$ & $t_{\text {gel }}(\min )$ & $R^{2}$ \\
\hline 90 & 0.050 & 56.9 & 0.862 \\
100 & 0.056 & 21.7 & 0.949 \\
110 & 0.067 & 10.3 & 0.957 \\
120 & 0.058 & 7.0 & 0.839 \\
\hline
\end{tabular}

Table 4

Heat of polymerization, Di Benedetto's equation, cure kinetics with Kamal-Sourour global model and gelation point of the polysilazane system PSZ20 with 1 wt $\%$ of dicumyl peroxide.

\begin{tabular}{lll}
\hline$H_{\text {tot }}$ & $228.5 \mathrm{~J} / \mathrm{g}$ & \\
Di Benedetto's equation & $\lambda=0.74$ & $T_{g 0}=181.2 \mathrm{~K}$ \\
Cure kinetics (Kamal-Sourour) & $k_{01}=2.24 \cdot 10^{13} \mathrm{~s}^{-1}$ & $E_{a 1}=125.64 \mathrm{~kJ} / \mathrm{mol}$ \\
& $k_{02}=1.70 \cdot 10^{16} \mathrm{~s}^{-1}$ & $E_{a 2}=141.25 \mathrm{~kJ} / \mathrm{mol}$ \\
Gelation point & $m=2.71$ & $n=1.38$ \\
\hline
\end{tabular}

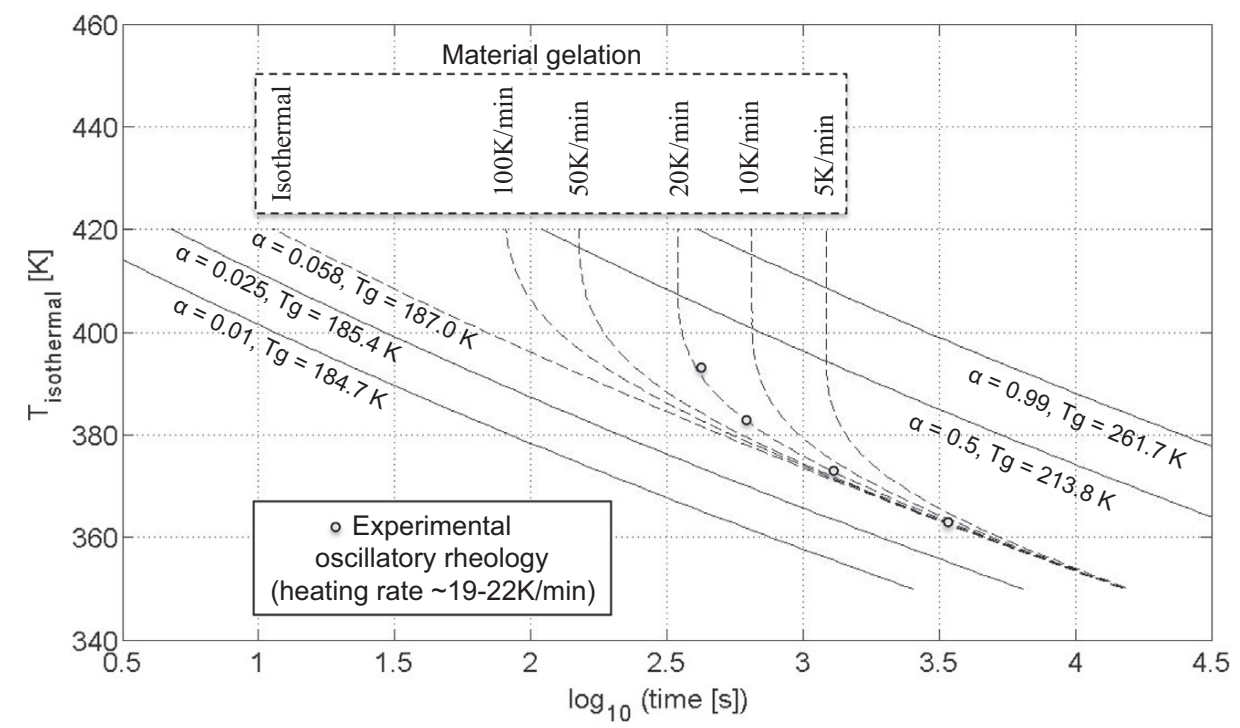

Fig. 12. Isothermal and pseudo-isothermal ( $100 \mathrm{~K} / \mathrm{min}, 50 \mathrm{~K} / \mathrm{min}, 20 \mathrm{~K} / \mathrm{min}, 10 \mathrm{~K} / \mathrm{min}, 5 \mathrm{~K} / \mathrm{min})$ TTT diagrams for the polysilazane system PSZ20 with $1 \mathrm{wt} \%$ of dicumyl peroxide. Grey points are the experimental results obtained during oscillatory rheology tests at $363 \mathrm{~K}, 373 \mathrm{~K}, 383 \mathrm{~K}$ and $393 \mathrm{~K}$.

$$
\begin{aligned}
& \alpha_{\text {gel }}=\frac{\sum_{i} \alpha_{g e l, i} \cdot R_{i}^{2}}{\sum_{i} R_{i}^{2}} \\
& R_{i}^{2}=R_{f i t 1, i}^{2} \cdot R_{f t 2, i}^{2}
\end{aligned}
$$

where $R_{f i t, 1,}^{2}, R_{f t 2, i}^{2}$ and $R_{i}^{2}$ are respectively the correlation coefficients of the two fitting lines and the overall correlation coefficients for each curing temperature, $\alpha_{g e l, i}$ is the crossover between the two fitting lines and $\alpha_{g e l}$ is the gelation point, computed as a geometric average of the values identified for the four curing temperatures. The gelation point obtained for this system is 0.058 . The results for the four curing temperatures are summarized in Table 3.

\section{TTT diagram}

The results obtained for this system are summarized in Table 4. According to these results it is possible to plot the gelation curve in a Time-Temperature-Transformation diagram, using the Kamal-Sourour global model. This diagram can be plotted under strict isothermal conditions (instantaneous temperature change up to the curing temperature) or under pseudo-isothermal conditions (finite heating rate up to the curing temperature). The isoconversional curves are plotted in Fig. 11 for different degrees of cure, from $1 \%$ to $99 \%$, showing the evolution of the conversion of the material. Pseudoisothermal curves show in the same figure the role played by the initial heating rate on the curve: when the heating rate 
slows down $(100 \mathrm{~K} / \mathrm{min})$, the gelation of the system begins to take place during the heating rate and not during isothermal curing, for temperatures higher than $420 \mathrm{~K}$ (this temperature decreases with the heating rate).

In Fig. 12, the experimental data (grey circles), obtained with a heating rate between 19 and $22 \mathrm{~K} / \mathrm{min}$, and used to identify the gelation point, are close to the gelation curve simulated with a heating rate of $20 \mathrm{~K} / \mathrm{min}$, and confirm the relevance of considering the temperature ramp in the gelation identification.

Instead of plotting the usual vitrification curve on this TTT diagram, which would be located in a temperature range between $181 \mathrm{~K}\left(-92^{\circ} \mathrm{C}\right)$ and $260 \mathrm{~K}\left(-13^{\circ} \mathrm{C}\right)$ without any practical interest for composite processing, the glass transition temperature was mentioned for each isoconversional curve. Moreover in the temperature range of the glass transition, the gelation time is higher than $2 \cdot 10^{10} \mathrm{~s}$, which is out of the validity range of the model.

\section{Conclusions}

The cure kinetics of the polysilazane system PSZ20 with dicumyl peroxide at $1 \mathrm{wt} \%$ was studied under both isothermal and dynamic conditions. A set of DSC dynamic scans allow computing the heat of polymerization of the system, which value is $229 \mathrm{~J} / \mathrm{g}$. Several DSC isothermal analyses were carried out at different curing temperatures (363-393 K) and durations ( $5 \mathrm{~min}$ to $48 \mathrm{~h}$ ) to identify the Di Benedetto's equation for this system and a Kamal-Sourour phenomenological model. A $T_{g 0}$ of $181 \mathrm{~K}\left(-92^{\circ} \mathrm{C}\right)$ and a $T_{g_{\infty}}$ of $260 \mathrm{~K}\left(-13^{\circ} \mathrm{C}\right)$ were obtained. The kinetic model was carried out considering an initial degree of conversion, which allows accounting for the effect of the initial heating rate before isothermal cure. This model uses two rate constants. A first activation energy of $126 \mathrm{~kJ} / \mathrm{mol}$ is obtained. The second activation energy is $141 \mathrm{~kJ} / \mathrm{mol}$, and it allows well reproducing the anisothermal peak, for different heating rates. The numerical simulations of the conversion advancement of the system are in good agreement with both isothermal and dynamic experimental analyses, especially for low degree of cure and for the highest conversion rate ranges. The discrepancy between model and experimental data occurs for a degree of cure greater than 0.9: this disagreement is probably generated by the simplicity of the kinetic equations, which cannot allow taking into account the degradation of the dicumyle peroxide and the polymerization of the system at the same time. Other approaches should be tried to improve the modelling of the system, as a cure kinetic composed of two (or more) equations or a fully mechanistic model. However, this error does not prevent to properly model material gelation, which takes place at a low degree of cure, where the model is in good agreement with experimental data. The gel point was obtained with the loss modulus inflexion criterion, according to Harran and Laudouard [30], for four isothermal oscillatory rheology tests. The conversion degree at the gel point $\left(\alpha_{g e l}=0.058\right)$ is obtained by plotting the loss modulus vs. the degree of cure, using the kinetic model previously obtained. According to the kinetic model, a set of isothermal and pseudo-isothermal gelation curves are plotted in a TTT diagram.

\section{Acknowledgements}

The collaboration with Snecma and Herakles is gratefully acknowledged. This work was supported under the PRC Composites, French research project funded by DGAC, involving SAFRAN Group, ONERA and CNRS (Contract reference number: 1554448A).

\section{References}

[1] P. Schutzenberger, A. Colson, Silicon, C. R. Hebd. Seances Acad. Sci. 93 (1885) 1508-1511.

[2] O. Glemser, K. Beltz, P. Naumann, Zur Kenntnis des Systems Silicium-Stickstoff, Zeitschrift für Anorg. und Allg. Chemie 291 (1-4) (1956) 51-66.

[3] B.J. Aylett, G.M. Burnett, L.K. Peterson, N. Ross, Thermal degradation of polymers, SCI Monogr. 13 (1961) 5-11.

[4] E. Kroke, Y.L. Li, C. Konotschny, E. Lecomte, C. Fasel, R. Riedel, Silazane derived ceramics and related materials, Mater. Sci. Eng. 26 (2000) 97-199.

[5] D. Seyferth, G.H. Wiseman, High-yield synthesis of Si3N4/SiC ceramic materials by pyrolysis of a novel polyorganosilazane, Commun. Am. Ceram. Soc. 27 (7) (1984) 132-133.

[6] Y. Blum, R.M. Laine, Catalytic methods for the synthesis of oligosilazanes, Organometallics 5 (1986) 2081-2086.

[7] R.M. Laine, Transition metal catalysed synthesis of oligo- and poly-silazanes, Platin. Met. Rev. 32 (2) (1988) 64-71.

[8] J.M. Schwark, Isocyanate-modified polysilazane ceramic precursors, Polym. Prep. 32 (1991) 567-568.

[9] J.M. Schwark, M.J. Sullivan, Isocyanate-modified polysilazanes: conversion to ceramic materials, Mater. Res. Soc. Proc. 271 (1992) $807-812$.

[10] D. Seyferth, C. Strohmann, N.R. Dando, A.J. Perrotta, Poly(ureidosilazanes): Preceramic Polymeric Precursors for Silicon Carbnitride and Silicon Nitride. Synthesis, Characterization and Pyrolytic Conversion to Si3N4/SiC Ceramics, Chem. Mater. 7 (1995) 2058-2066.

[11] F. Aldinger, M. Weinmann, J. Bill, Precursor-derived Si-B-C-N ceramics, Pure Appl. Chem. 70 (1998) 439-448.

[12] Y.L. Li, E. Kroke, R. Riedel, C. Fasel, C. Gervais, F. Babonneau, Thermal cross-linking and pyrolytic conversion of poly(ureamethylvinyl)silazanes to silicon-based ceramics, Appl. Organomet. Chem. 15 (2001) 820-832.

[13] S. Reschke, C. Haluschka, R. Riedel, Z. Lences, D. Galusek, In situ generated homogeneous and functionally graded ceramic materials derived from polysilazane, J. Eur. Ceram. Soc. 23 (2003) 1963-1970.

[14] E. Klatt, A. Frass, M. Friess, D. Koch, H. Voggenreiter, Mechanical and microstructural characterisation of SiC- and SiBNC- fibre reinforced CMCs manufactured via PIP method before and after exposure to air, J. Eur. Ceram. Soc. 32 (2012) 3861-3874.

[15] C.P. GmbH, Technical Information: Ceraset ${ }^{\circledR}$ PSZ 20, 2011.

[16] Technical Bulletin 1, KiON Ceraset polyureasilazane and KiON ceraset polysilazane 20 heat-curable resins of KiON Corporation".

[17] L.A. Liew, Y. Liu, R. Luo, T. Cross, L. An, V.M. Bright, M. Dunn, J.W. Daily, R. Raj, Fabrication of SiCN MEMS by photopolymerization of pre-ceramic polymers, Sens. Acttuators A Phys. Artic. 95 (2002) 143-151.

[18] M. Schulz, M. Borner, J. Gottert, T. Hanemann, J. Hausselt, G. Motz, Cross linking behaviour of preceramic polymers effected by UV- and synchrotron radiation, Adv. Eng. Mater. 6 (2004) 676-680.

[19] A. Kojima, S. Hoshii, T. Muto, Characteristics of polysilazane compound and its application as coating for carbon materials, J. Mater. Sci. Lett. 21 (10) (2002) 757-760. 
[20] C. Vakifahmetoglu, I. Menapace, A. Hirsch, L. Biasetto, R. Hauser, R. Riedel, P. Colombo, Highly porous macro- and micro-cellular ceramics from a polysilazane precursor, Ceram. Int. 35 (2009) 3281-3290.

[21] S.A.C. Abarca, O. Flores, A.L.G. Prette, G.S. Barroso, T. Coan, G. Motz, R.A.F. Machado, Synthesis and thermal characterization of silicon-based hybrid polymer, Chem. Eng. Trans. 32 (2013) 1621-1626.

[22] T. Konegger, R. Patidar, R. Bordia, A novel processing approach for free-standing porous non-oxide ceramic supports from polycarbosilane and polysilazane precursors, J. Eur. Ceram. Soc. 35 (9) (2015) 2679-2683.

[23] J.M. Schwark, Isocyanate- and isothiocyanate- modified polysilazane ceramic precursors, 1988.

[24] J.M. Schwark, (Thio)amide-modified silazane polymer composition containing a free radical generator, 1989.

[25] J.M. Schwark, Peroxide-substituted polysilazanes, 1992.

[26] A. Lavedrine, D. Bahloul, P. Goursat, N. Choong Kwet Yive, R. Corriu, D. Leclerq, H. Mutin, A. Vioux, Pyrolysis of polyvinylsilazane precursors to silicon carbonitride, J. Eur. Cearmic Soc. 8 (4) (1991) 221-227.

[27] J. Bill, J. Seitz, G. Thurn, J. Dürr, J. Canel, B. Janos, A. Jalowiecki, D. Sauter, S. Chempp, H.-P. Lamparter, J. Mayer, F. Aldinger, Structure analysis and properties of Si-C-N ceramics derived from polysilazanes, Phys. Status Solidi 166 (1998) 269.

[28] Lanxide company, Technical Bulletin of CERASET ${ }^{\circledR}$ SN Inorganic Polymer, 1997.

[29] M.F. Gonon, S. Hampshire, J.P. Disson, G. Fantozzi, A polysilazane precursor for Si-C-N-O matrix composites, J. Eur. Ceram. Soc. 15 (1995) 683-688.

[30] D. Harran, A. Laudouard, Caractérisation de la gélification d'une résine thermodurcissable par méthode rhéologique, Rheol. Acta 24 (1985) 596-602.

[31] A.T. Di Benedetto, Prediction of the glass transition temperature of polymers: a model based on the principle of corresponding states, J. Polym. Sci. Part B 25 (1987) 1949-1969.

[32] J.P. Pascault, R.J.J. Williams, Glass transition temperature versus conversion relationships for thermosetting polymers, J. Polym. Sci. Part B Polym. Phys. 28 (1990) 85-95.

[33] M.J. Richardson, N.G. Savill, Derivation of accurate glass transition temperatures by differential scanning calorimetry, Polymer (Guildf) 16 (10) (1975) $753-757$.

[34] M.R. Kamal, S. Sourour, Kinetics and thermal characterization of thermoset cure, Polym. Eng. Sci. 13 (1) (1973) 59-64.

[35] M. Ivankovic, L. Incarnato, J.M. Kenny, L. Nicolais, Curing kinetics and chemo-rheology of epoxy/anhydride system, J. Appl. Polym. Sci. 90 (2003) 30123019.

[36] F.X. Perrin, T.M.H. Nguyen, J.L. Vernet, Chemico-diffusion kinetics and TTT cure diagrams of DGEBA-DGEBF/amine resins cured with phenol catalysts, Eur. Polym. J. 43 (12) (2007) 5107-5120.

[37] N. Rabearison, C. Jochum, J.C. Grandidier, A cure kinetics, diffusion controlled and temperature dependent, identification of the Araldite LY556 epoxy, J. Mater. Sci. 46 (3) (2010) 787-796.

[38] L.M. Lopez, A.B. Cosgrove, J.P. Hernandez-Ortiz, T.A. Osswald, Modeling the vulcanization reaction of silicone rubber, Polym. Eng. Sci. (2007) 675-683.

[39] J.A. Nelder, R. Mead, A simplex method for function minimization, Comput. J. 7 (4) (1965) 308-313.

[40] J.C. Lagarias, J.A. Reeds, M.H. Wright, P.E. Wright, Convergence properties of the nelder-mead simplex method in low dimensions, SIAM J. Optim. 9 (1) (1998) 112-147.

[41] I. Di Somma, R. Marotta, R. Andreozzi, V. Caprio, Dicumyl peroxide thermal decomposition in cumene: development of a kinetic model, Chem. Eng. Trans. 24 (2011) 73-78.

[42] P.I. Karkanas, I.K. Partridge, Cure modeling and monitoring of epoxy/amine resin systems. II. Network formation and chemoviscosity modeling, J. Appl. Polym. Sci. 77 (2000) 2178-2188.

[43] H. Winter, Can the gel point of a cross-linking polymer be detected by the $G^{\prime}-G^{\prime \prime}$ crossover?, Polym Eng. Sci. 27 (22) (1987) $1698-1702$.

[44] R. Chavez, E. Ionescu, C. Balan, C. Fasel, R. Riedel, Effect of ambient atmosphere on crosslinking of polysilazanes, J. Appl. Polym. Sci. 119 (2011) 794802.

[45] O. Flores, L. Heymann, G. Motz, Rheological behaviour of tailored polysilazanes melts for the processing of SiCN ceramics: viscoelastic properties and thermal stability, Rheol. Acta 54 (2015) 517-528.

[46] J.R. Dormand, P.J. Price, A family of embedded Runge-Kutta formulae, J. Comput. Appl. Math. 6 (1) (1980) 19-26. 